\title{
Vital role of water in longevity of SARS-CoV-2 and enhancing its binding with human cells
}

\author{
Gholamabbas Parsafar ${ }^{1}$ (D) Vinay Reddy ${ }^{2}$
}

Received: 14 December 2020 / Accepted: 29 May 2021 / Published online: 4 June 2021

(C) Iranian Chemical Society 2021

\begin{abstract}
Based on our present knowledge on SARS-CoV-2 virus, which is collectively summarized in this work, it is shown that water plays a crucial role in stabilizing the virus, in such a way that its viability may reduce from a few days to a few seconds in the absence of water layer. Water not only provides a protective shell for the virus in which it is enveloped, but enhances its binding with the human cell. Therefore, one may conclude that the dehydration of the hydrated virus makes it much more vulnerable, due to the fact that if it is exposed to many chemicals it will be deactivated; even by particles in air, such as ozone, singlet oxygen and pollutants. Thermodynamically, the dehydration may be facilitated at higher temperature, low humidity, and exposure to deliquescent materials. We have concluded that if the contaminated air passes over or through some water absorbents, like calcium chloride, with enough time contact, the virus is expected to become dehydrated and deactivated shortly afterward. If the time contact is not enough for the deactivation, the air may be exposed to the blue or UVC lights as well. The conclusion is based on the hydrated-dehydrated equilibrium of the coronavirus introduced in this work.
\end{abstract}

Keywords SARS-CoV-2 virus · Vulnerability of virus $\cdot$ Dehydrated virus $\cdot$ Covid-19 disease

\section{Introduction}

SARS-CoV-2, more commonly known as the Coronavirus (shown in Fig. 1), is a virus that originated in Wuhan, China in late 2019 [1]. In the past there have been other strands of the virus such as SARS-CoV and MERS-CoV. SARS-CoV originated in China in 2003 while MERS-CoV originated in the Middle East in 2012 [2, 3]. After 2-3 months in China, it spread throughout the whole world.

SARS-CoV-2, which will also be referred to as the virus hereafter, is an airborne, single stranded RNA virus that infects people by physical or airborne contact in the vicinity of the CoV-19 patient. There are 7 different Coronaviruses, of which 3 of them are deadly. Those three are the MERSCoV, SARS-CoV-2 and SARS-CoV [4]. The 4 non-lethal

Gholamabbas Parsafar

g.parsafar@gmail.com; parsafar@sharif.edu

Vinay Reddy

vreddy@sfhs.com

1 Department of Chemistry, Sharif University of Technology, Azadi Ave., 11365-11155 Tehran, Iran

2 Mega Prep Academy, San Jose, CA 95129, USA viruses are 229E, NL63, OC43, and HKU1 [5]. In this paper, the focus will be on the SARS-CoV-2 and Covid-19 disease. The virus is encapsulated in the particles from mucus or spit. Normally, the transmission of droplets contaminated with the virus happens when a person speaks, coughs, or sneezes, because the droplets are sprayed in the area. The size of $95 \%$ droplets is between 1 and $100 \mu \mathrm{m}$ depending on the droplets from a person's cough or voice. Most of the droplets ranged from 4 to $8 \mu \mathrm{m}$ [6]. However, it is estimated from a study on SARS-CoV that a droplet is less than $20 \mu \mathrm{m}$ and that value continually decreases due to detachment of water molecules [7]. In cases of direct transmission, contact with an infected person or surface can cause the secretion of fomites which leads to the virus infecting another person [8]. The virus can also be self-transmitted by contaminated fomites. One of the most common transmission types is poor hygiene or touching of the face with a contaminated surface [9]. Another way of transmission is through feces.

In fact the recent investigations show that a significant number of infected patients with the virus are accompanied by persistent shedding of virus RNA in their feces. The presence of SARS-CoV-2 in feces raises the potential of survey for virus RNA to inform epidemiological monitoring of COVID -19, which is known as the wastewater-based 


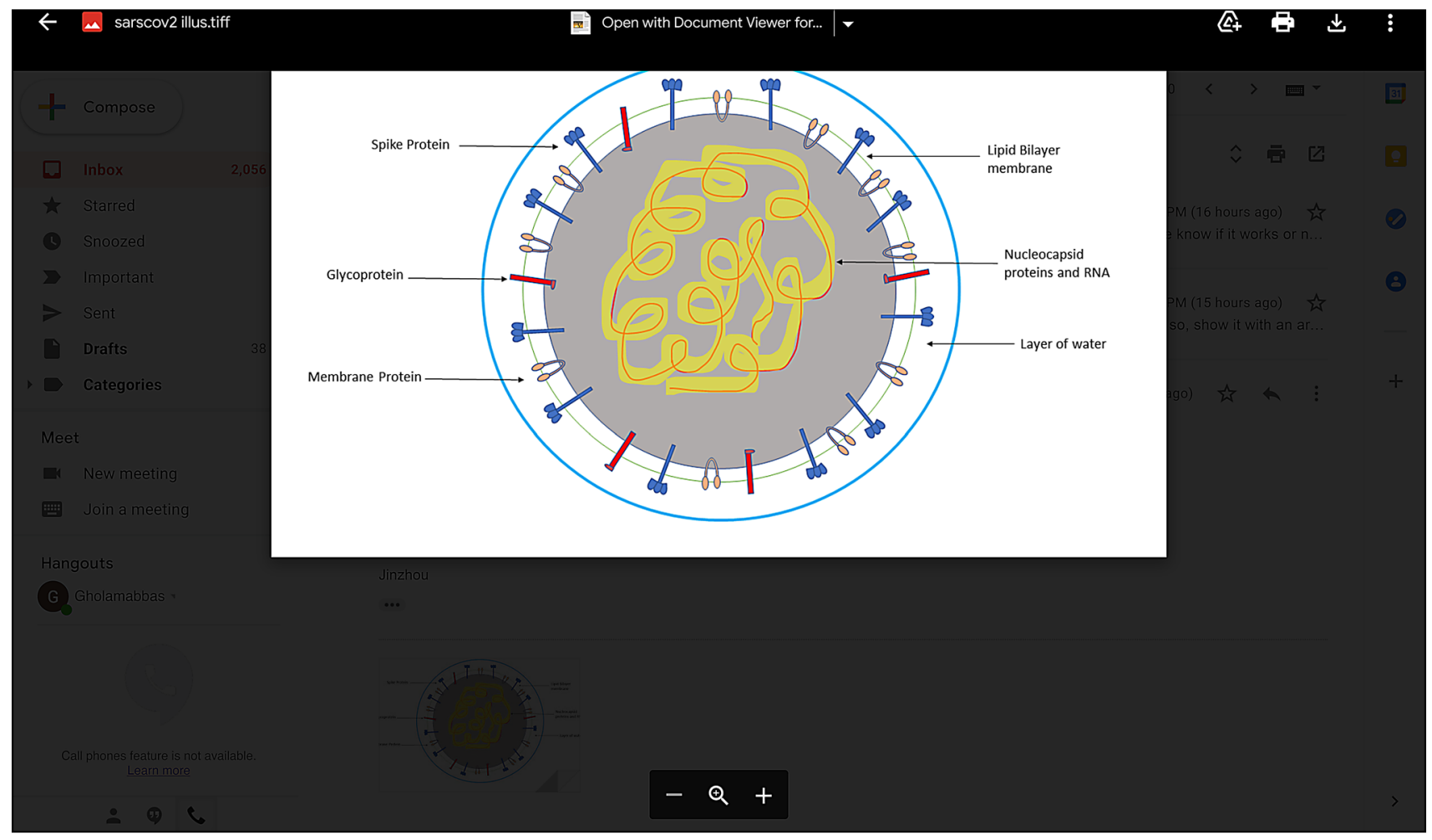

Fig.1 All segments of an airborne coronavirus are enveloped in a protective water layer

epidemiology or environmental surveillance [10]. The sewage samples of six cities and one airport in Netherlands were tested using four qRT-PCR assays, three targeting the nucleocapsid gene and one the enveloped gene. The study shows in one case the presence of the virus in the sewage 6 days before the first case was reported. As the prevalence of COVID-19 in these locations increased, the RNA signal detected by each qRT-PCR assay increased as well. This increase correlated significantly with the increase in reported COVID-19 prevalence. The detection of the virus RNA in sewage, even when the COVID-19 prevalence is low, and the correlation between concentration in sewage and reported prevalence of COVID-19, indicates that sewage surveillance could be a sensitive tool to monitor the circulation of the virus in a community, and may be served as a sensitive tool for early warning for increasing virus circulation [11].

The structure of the virus is similar to the other coronaviruses such as SARS-CoV and MERS-CoV. SARS-CoV-2 has glycoprotein spikes, which have glycan shields that help the virus to attach to the human body [12]. It also has a $\mathrm{M}$ protein, which gives the virus structure, and it has envelope protein, which helps to protect the genetic material of the protein $[13,14]$. The $\mathrm{M}$ protein works with the $\mathrm{E}$ protein to form the structure of the virus $[13,14]$. The outside structure of the virus has a lipid bilayer membrane with protein membrane receptors like the $\mathrm{E}$ protein and $\mathrm{M}$ protein on the membrane $[14,15]$. The Lipid membrane also helps for the receptor to stick onto a human cell and infects it [15]. Inside the cell, RNA and N Protein are stored. SARS-CoV-2 acts as a retrovirus and produces its own DNA through RNA [1]. The virus in order to infect someone uses its actual spikes [16]. Droplets that contain the virus usually range from 4 to $8 \mu \mathrm{m}[6]$.

The symptoms of SARS-CoV-2 include fever or chills, shortness of breath, fatigue, muscle or body aches, headache, loss of taste or smell, sore throat, congestion, nausea or vomiting, and diarrhea [17]. However, the most common symptom is fever or cough. These symptoms can be seen anywhere from 2 to 14 days after contracting the virus [18].

SARS-CoV-2 survives differently on different surfaces, temperatures, and humidities. In air, it travels up to $1 \mathrm{~m}$. The virus can stay in the air for up to $8 \mathrm{~min}$ at $23^{\circ} \mathrm{C}$ and $27 \%$ humidity per 1000 virions [19]. On cold, solid, metal surfaces, it lasts significantly longer. SARS-CoV-2 and SARS-CoV have similar survival times. On copper, the virus survives for $4 \mathrm{~h}, 24 \mathrm{~h}$ on cardboard, $48 \mathrm{~h}$ on stainless steel, and $72 \mathrm{~h}$ on plastic [20]. SARS-CoV-2 has a lower chance of survival in very humid and hot weather. In one study, at $38{ }^{\circ} \mathrm{C}$ and $95 \%$ humidity, SARS-CoV lost viability. At lower temperatures like $6{ }^{\circ} \mathrm{C}$ and lower humidities, SARS-CoV and MERS-CoV were more viable to survive. Even at ambient temperatures like $16-28{ }^{\circ} \mathrm{C}$, SARS-CoV survived and 
there was growth stimulated [21]. In addition, Scientists also did a study in which they set a temperature in a laboratory space to $3{ }^{\circ} \mathrm{C}$ and measured the virus growth. After this, they increased the temperature to $13{ }^{\circ} \mathrm{C}$ and saw that there was an inverse correlation of SARS-CoV-2 cases if the temperature was increased. In addition, at absolute humidity, deaths in Covid-19 patients plummeted [21]. They also saw that in high humidity and high temperature areas, SARS-CoV-2 did not reproduce [21]. There is an inverse correlation between the increase in temperature and the death of the virus. In addition, a dry and less humid environment kills the virus most effectively [22]. The reason for the death of SARS$\mathrm{CoV}-2$ in hot temperatures is because the virus denatures and loses its structure.

SARS-CoV-2 is a virus that has killed a significant number of people worldwide. Research into SARS-CoV-2 while not limited has not really gone into the thermodynamics and stability of the SARS-CoV-2. The purpose of this paper is to show that all variables; such as high temperature, low humidity, and presence of water absorbent materials; which help the dehydration of airborne viruses, also leads to deactivation of the virus. Since the dehydrated virus is vulnerable to many chemicals, even species like singlet oxygen, ozone, and pollutants in air, we show that the thermodynamic investigation of the dehydration can shed some lights on how to fight against the airborne virus. Prior to that, the structural, physical, and chemical properties of the virus will be studied.

\section{Physical properties}

The size of SARS-CoV-2 is very small. In aerosols, SARSCoV-2 was found to be categorized into two different sizes sub-micrometer, which ranges from 0.25 to $1 \mu \mathrm{m}$, and supermicrometer, which ranges from 1 to $2.5 \mu \mathrm{m}$ [23]. Normal droplets of SARS-CoV-2 were found to be from 4 to $8 \mu \mathrm{m}$ and $95 \%$ of droplets ranged from 1 to $100 \mu \mathrm{m}$ [6]. The actual size of SARS-CoV-2 is approximately $60-140 \mathrm{~nm}$. It is part of the betaCoV category. The shape of SARS-CoV-2 is elliptical, round, and usually pleomorphic [24]. Approximately, SARS-CoV-2 is $10^{\wedge} 3 \mathrm{MDa}$, which is about 1 femtogram [25]. The charge of the proteins on the surface of the virus is evenly distributed in an isoelectric space, and therefore, it is neutral. Decreasing the $\mathrm{pH}$ in that glycoprotein on the surface of SARS-CoV-2 shows a positive charge. A hypothetical visualization of the charge by Sudip Chatarjee shows that the charge on the spike protein per $\mathrm{nm}$ was $(2240 \times$ $10-19 /$ ) C [26].

SARS-CoV-2 does not survive in the presence of soap. Scientists conducted an experiment where they tested SARSCoV-2's resistance against soap powder, $0.05 \%$ active Chlorine, and $0.25 \%$ Chlorine. The virus died by $98.83 \%$ in soap powder, $96.62 \%$ in $0.05 \%$ Chlorine, and $99.98 \%$ in $0.25 \%$ Chlorine [27]. From the data, it can be inferred that the virus dies mostly against Chlorine, but it similarly dies at a similar rate to soap. There are three ways for which soap cleanses the virus. They are the membrane rupture mechanism, simple elution mechanism, and viral entrapment mechanism [28]. The first mechanism, the rupture mechanism, happens when the soap comes into contact with the virus via a hydrophobic-hydrophobic interaction. When the lipids from the soap and the virus come into contact, the lipid layer on the virus becomes saturated, and destroys the virus, making it into fragments [28]. The second mechanism, the simple elution mechanism, happens as a result of the very low surface tension in soap [27]. As a result of the low surface tension, soap can easily enter the dirt where the soap is being applied and also enter near the virions. Soap then can moisten the surface and charge and stabilize the particles. The charged virus cannot harm anything and is flushed out in the process of a person washing their hands. The last type is the viral entrapment mechanism [28]. This happens since soap has a hydrophobic section. As a result, the soap traps the virus through a hydrophobic-hydrophobic interaction, and as a result of that, the water carrying the soap drags the virus away. This mechanism is unlikely since the virus is bigger than soap molecules and as a result, it is unlikely that the virus will be fitted into the soap. The most likely mechanisms are the elution mechanism or the rupture mechanism [28].

In relation to SARS-CoV-2's interaction with soap, the virus interaction with water is very different. A new study actually shows that water helps the virus to stick to the human body. SARS-CoV-2 binds to a protein receptor on the body ACE2, which due to the hydrophobic interactions or the increased Van der Waals forces between the receptors. The study found that the human receptor ACE2 has a lot of water and the interfacial water is key to help SARS-CoV-2 to bind properly [29].

SARS-CoV-2 is highly stable in aqueous solutions [30]. Infectivity of the virus is strongly reduced upon drying. After $1 \mathrm{~h}$ drying on a metal disk, it reduces up to 100 -fold [31]. The membrane of the virus is a bilayer lipid and other proteins, in which the hydrophobic groups are enveloped in the hydrophilic parts [12]. There are some glycoprotein spikes on the outer shell of the membrane, with numerous hydrophilic groups [16]. Therefore, the outer shell of the whole virus is strongly hydrophilic. Hence, we expect that the virus itself is enveloped by a water film, as a protective layer, as shown in Fig. 1.

Strong dipole-ions interactions between the water film of the virus and the cation of soap or salt may cause the virus become vulnerable, due to penetration of the hydrophobic head of soap entering the hydrophobic 
part of the membrane, or the reaction of $\mathrm{Cl}^{-}$of salt with a polar bond of a spike.

The impact of water upon the infection of the virus was investigated by Ashish et al. [29]. They found that the interfacial water molecule plays a critical role in binding and in maintaining the stability of the virus-human cells.

\section{Interaction with light}

SARS-CoV-2 reacts differently to different types of light. In sunlight, SARS-CoV-2 dies easily. Researchers conducted an experiment for the decaying of SARS-CoV-2 under light [32]. The virus had a concentration of $1.31 \%$ in the solution with a $\mathrm{pH}$ of 7.4 and protein concentration of $3.58 \mathrm{mg} / \mathrm{ml}$ [32]. Scientists tested the decay rate at 3 different light levels. The temperature of the light was $20^{\circ} \mathrm{C}$. In the simulated saliva, the decay rate in $\% /$ minute at a high intensity light was $19 \% / \mathrm{min}$ to $27.2 \% / \mathrm{min}$, in medium light was $9.9 \% / \mathrm{min}$ to $12.9 \% / \mathrm{min}$, and in no light the virus decayed at a rate of $0.8 \pm 1.1 \% / \mathrm{min}$. In less than $20 \mathrm{~min}, 90 \%$ of all SARSCoV-2 in a saliva sample decayed [32]. The half-life of the virus was $6 \mathrm{~min}$. In sunlight, the virus aerosols have very little chance of survival due to the UV lights that are produced by the sun. The sun produces three types of UV rays, UVA, UVB, and UVC [33]. Previously, it was thought that only UVC rays could kill the virus; however, in a recent study, it was shown that UVA, UVB and UVC can all kill SARS-CoV-2 [32]. The sun emits UV rays. About $90-95 \%$ of all UV rays emitted by the sun are UVA rays while UVB rays make up the extra 5-10\% [33]. The UVC rays cannot pass through the ozone layer [33]. Sunlight kills all forms of SARS-CoV-2 [32].

Different wavelengths of light may also be able to kill the virus. For example, blue light is an antimicrobial against different forms of bacteria [34]. Similar to soap, blue light works in a way to disrupt the virus membrane [35]. By altering the membrane, blue light can disrupt the virus internally and cause it to break apart and die [35]. One study shows that a low dose of blue light at $450 \mathrm{~nm}$ disrupted the MRSA bacteria that was infecting patients [36]. The blue light disrupts the cell membrane's integrity and results in the organelles being destroyed and eventually the bacteria [36]. Due to effects of blue light on other bacteria and viruses, it can be inferred that blue light can also disrupt SARS-CoV-2 [34]. Blue light and visible light have larger wavelengths compared to UV light, but they are able to thoroughly damage the virus.

Infrared light and red light can also help to stop inflammation in the lungs and respiratory diseases [34]. Using a wavelength of $650 \mathrm{~nm}$, scientists discovered that a $1 \mathrm{~h}$ treatment of inflation in a person removed several inflammation levels [37]. In addition, infrared and red light decreased inflammation in the alveoli, which is one area that SARSCoV-2 targets. It also decreased the amount of collagen and inflammatory cells in the regions and topped the tension in the lungs in order for the inflammation to reduce. While it doesn't actually kill the virus, the light near the infrared and red light spectra is known to help stop inflammation and generally improve the condition of the patient [37].

Blue light and UV light are the most efficient light killers of SARS-CoV-2 since they help to denature the virus through disrupting its membrane [32, 34]. Both UV light and blue light are readily available in nature and can destroy virion aerosols most efficiently.

\section{Chemical properties}

The spikes on SARS-CoV-2 are made up of glycoproteins [12]. These glycoproteins help to invade and attach the virus to the human cells [16]. The membrane of the virus is a lipid bilayer. This lipid bilayer is made of phospholipids. Phospholipids have hydrophilic and hydrophobic segments, the hydrophobic section is made of fatty acids, and the hydrophilic section includes phosphate, choline, and glycerol. The hydrophobic section is enveloped in hydrophilic parts [24].

Glycoproteins are proteins that contain certain covalently attached sugar residues. The hydrophilic and polar characteristic of sugars may dramatically change the chemical characteristic of the protein to which they are attached. There are three types of glycoproteins: N-linked glycoproteins, O-linked glycoproteins, and nonenzymatic glycosylated glycoproteins [16].

The virus is rapidly deactivated by acidic solutions with $\mathrm{pH}$ less than 3 [38]. In a study, scientists found that the stomach pain was linked to SARS-CoV-2 [39]. Scientists tested 204 subjects and found that their viral load was much greater for those who were infected with the virus [39]. Many patients are also given antacids, which results in a $\mathrm{pH}$ of 4 to 5 . This is not nearly acidic enough to kill the virus $[38,40]$. SARS-CoV-1 required a $\mathrm{pH}<3.0$ or a $\mathrm{pH}>13.0$ in order to die [38]. Because of the similarity of the structure of SARS-CoV-1 and SARS-CoV-2, it can be assumed that any acid with a pH lower than 3.0 can kill SARS-CoV-2 [38, 40]. That means that weak acids cannot kill the virus.

Glycerol-fatty acid, phosphate-glycerol, choline-phosphate, and peptide bonds can be broken apart in strongly acidic and basic solutions. The virus is deactivated in acidic with $\mathrm{pH}$ smaller than 3 and basic solutions with $\mathrm{pH}$ larger than 10 [38]:

$\mathrm{R}-\mathrm{COO}-\mathrm{CH}_{2}-\stackrel{\mathrm{H}^{+}}{\underset{\mathrm{OH}^{-}}{\longrightarrow}} \mathrm{RCOO}^{-}+\mathrm{HOCH}_{2}^{-}$ 
$-\mathrm{CH}_{2}-\mathrm{O}-\mathrm{PO}_{2}^{-}-\mathrm{O}-\mathrm{C}_{5} \mathrm{H}_{13} \mathrm{~N}^{+} \underset{\mathrm{OH}^{-}}{\stackrel{\mathrm{H}^{+}}{\longrightarrow}}-\mathrm{CH}_{2} \mathrm{OH}+\mathrm{HO}-\mathrm{PO}_{2}^{-}-\mathrm{O}-\mathrm{C}_{5} \mathrm{H}_{13} \mathrm{~N}^{+}$

$\mathrm{C}_{5} \mathrm{H}_{13} \mathrm{~N}^{+}-\mathrm{O}-\mathrm{PO}_{2}^{-}-\mathrm{O}-\mathrm{CH}_{2}-\underset{\mathrm{OH}^{-}}{\stackrel{\mathrm{H}^{+}}{\longrightarrow}}$ Choline $+\mathrm{HO}-\mathrm{PO}_{3}^{-}-\mathrm{CH}_{2}-$

$-\mathrm{CO}-\mathrm{NH}-\underset{\mathrm{OH}^{-}}{\stackrel{\mathrm{H}^{+}}{\longrightarrow}}-\mathrm{COOH}+\mathrm{H}_{2} \mathrm{~N}-$

Chlorine which is an oxidant also kills the virus. As discussed earlier in the paper, soap mixed with $0.05 \%$ chlorine increased the inactivation of the virus by $1 \%$ [27]. Pure $\mathrm{Cl}_{2}$ can definitely kill the virus. Chlorine is also in bleach, which is its basic ingredient [40]. Chlorine reacts with $\mathrm{Cl}_{2}(\mathrm{~g})+\mathrm{H}_{2} \mathrm{O}(1) \rightleftarrows \mathrm{HCl}+\mathrm{HOCl}$ water as: Hypochlorous acid reacts with proteins to produce $\mathrm{N}$-chloro-compounds:

$\mathrm{R}-\mathrm{C}(\mathrm{H})(\mathrm{COOH})\left(\mathrm{NH}_{2}\right)+\mathrm{HOCl} \rightarrow \mathrm{R}-\mathrm{C}(\mathrm{H})(\mathrm{COOH})(\mathrm{NHCl})+\mathrm{H}_{2} \mathrm{O}$

$\mathrm{R}-\mathrm{C}(\mathrm{H})(\mathrm{COOH})(\mathrm{NHCl})+\mathrm{HOCl} \rightarrow \mathrm{R}-\mathrm{C}(\mathrm{H})(\mathrm{COOH})\left(\mathrm{NCl}_{2}\right)+\mathrm{H}_{2} \mathrm{O}$

Therefore, aqueous solutions of chlorine can kill the virus by oxidizing it.

Chemical species such as ozone, singlet oxygen, nitric oxide, air pollutants, and exposures to radiation can oxidize phospholipids [41]. Ozone, pollutants in air and radiation lead to oxidation of proteins $[42,43]$. Therefore, if the virus is exposed to air, both its membranes and spikes will be damaged.

Hand sanitizer and rubbing alcohol also works similarly to soap in its ability to inactivate the coronavirus [38, 44]. Even though it is slightly less effective, it is still enough for the disinfection. Alcohol free hand sanitizers are more powerful than alcohol-based hand sanitizers [38]. There are many types of hand sanitizers such as foam, gels, and liquid hand sanitizers [45-47]. Liquid hand sanitizer is the most powerful out of all of these [48]. There are also spray hand sanitizers, but it is not safe since it could be inhaled and is flammable [38]. Similarly, hand sanitizing wipes are also strong, but lack the longevity to be essential since if they are left out for too long, they lose their antiviral and antibacterial properties [41].

Overall, the virus is chemically weak against very active compounds. Though it can resist weak acids and bases, strong acids and bases are a remedy to the virus [39]. The integrity of the glycoproteins and membrane can be compromised if they come into contact with a strong base or acid [39]. Through the rupture mechanism, which also works in soap, the virus is rapidly deactivated since the membrane is breached and the virus falls apart [16]. This is similar to the reaction with oxidants, and sanitizers, and rubbing alcohol which also are strong effective compounds [27, 38]. It can be inferred that an antiviral would likely have the characteristic of a strong base or strong acid or an oxidant.

\section{Vapor pressure and thermodynamic stability of the hydrated virus}

The work, $\mathrm{d} w$, needed to increase the surface of a liquid by $\mathrm{d} \sigma$ is given by,

$\mathrm{d} w=\gamma \mathrm{d} \sigma$

where $\gamma$ is the surface tension of the liquid.

For a liquid at equilibrium with its vapor, the molar Gibbs free energy of both phases are equal:

$G_{v}=G_{l}$

The pressure of both phases is equal which is called the vapor pressure of the liquid. If an extra pressure of $\mathrm{d} P_{1}$ is applied on the liquid at the same temperature, its Gibbs free energy, $\mathrm{d} G_{1}$ increases by

$\mathrm{d} G_{l}=v_{l} \mathrm{~d} P_{l}$

where $v_{1}$ is the molar volume of the liquid. In order to restore the equilibrium, pressure of the vapor has to increase in such that the change at free energy of the gas, $\mathrm{d} G_{\mathrm{v}}$

$\mathrm{d} G_{v}=R T \mathrm{~d} \ln \left(P_{v}\right)$

be equal to that of the liquid phase: 
$v_{l} \mathrm{~d} P_{l}=R T \mathrm{~d} \ln \left(P_{v}\right)$

where $R$ is the gas constant and $T$ is absolute temperature. Note that the vapor is assumed to be ideal. Taking into account both initial and final states of equilibrium, the integration of both sides of Eq. 5 leads to

$P_{v}=P_{v}{ }^{0} e^{v_{l} \Delta P / R T}$

where $\Delta P=P_{1}-P_{\mathrm{v}}, P_{\mathrm{v}}{ }^{0}$ is the vapor pressure of the liquid at $T$, and $P_{\mathrm{v}}$ is its value when the extra pressure of $\Delta P$ is applied on the liquid. Note that the molar volume of liquid is assumed to be independent of pressure.

Considering a spherical droplet with radius $r$, its surface area is given by $\sigma=4 \pi r^{2}$, then Eq. 1 becomes

$\mathrm{d} w=8 \gamma \pi r \mathrm{~d} r$

The work $\mathrm{d} w$ can be considered as a force equal to $8 \gamma \pi r$ times the displacement $\mathrm{d} r$. If the force is divided by the surface area, we get the pressure on the droplet, $\Delta P$ as

$\Delta P=8 \gamma \pi r / 4 \pi r^{2}=2 \gamma / r$

which is the extra pressure on the droplet compared to the liquid bulk.

Therefore, the vapor pressure of the spherical droplet, $P_{\text {drop }}$, is related to its bulk liquid, $P_{\text {bulk }}$, by substituting $2 \gamma / r$ for $\Delta P$ into Eq. 6 [49]

$P_{\text {drop }}=P_{\text {bulk }} e^{2 \gamma v_{l} / r R T}$

If we assume that the surface tension of the hydrated virus is the same as that of water, $\gamma=72 \mathrm{mN} / \mathrm{m}$ at room temperature, the vapor pressure of the viral with $0.05 \mu \mathrm{m}$ in diameter is about $2 \%$ higher than that with $5.0 \mu \mathrm{m}$. Nevertheless, at lower temperatures and for larger values of the surface tension, the difference becomes more significant.

The dehydration of a viral droplet may be shown as

virus. $n \mathrm{H}_{2} \mathrm{O} \leftrightarrows$ virus $+n \mathrm{H}_{2} \mathrm{O}(g$, in air $)$

where $n$ is the number of $\mathrm{H}_{2} \mathrm{O}$ molecules accompanying a virus. This process is endothermic, which is in favor of hydrated viruses. However, the dehydration leads to increase in entropy, mainly due to the release of the water molecules as steam. Also, mixing of the water with air increases the entropy. Therefore, the driving force of dehydration is entropy. Thermodynamically, the free energy change, $\Delta G$, is given in terms of the enthalpy change, $\Delta H$, entropy change, $\Delta S$, and absolute temperature, $T$, as

$\Delta G=\Delta H-T \Delta S$
The overall direction of the process is determined by the sign of $\Delta G$. We may conclude that the higher temperature is in favor of the dehydration process.

\section{Conclusion and suggestion}

As far as we know, in addition to direct contact with the infected person, the virus transmission can take place by three different routes: (i) Touching a surface contaminated with the spit or oral fluid of the patient's mouth, cough, or sneeze, then touching the face with the hand. (ii) Fecal-oralroute, for that five paths have been specified, through which the food we eat may be contaminated [11]. (iii) Finally, airborne transmission, in which small droplets(less than about $5 \mu \mathrm{m}$ in diameter) may transport in air for a noticeable time period and distance, then be inhaled. The transmission by the first route can be easily brought under control, by wiping the surfaces with alcohol or other disinfected chemicals and washing hands frequently with soap. The transmission by the second route may also get under control, by adding chlorine, a strong acidic or basic solution to the contaminated sewer. However, before proper vaccination, the major challenge is how to protect people from the airborne viruses.

As recommended, the spread of covid-19 disease may be reduced by applying appropriate protocols; including face covering, social distancing, 14-day quarantine of people with some symptoms, wiping surfaces and frequent hand washing. These measures are certainly necessary but not adequate to get rid of the air-floating viral droplets.

As mentioned in this work, we know the following characteristics of the virus: (a) It has a much longer lifetime in water, compared to air; (b) In comparison to the metal surfaces, plastics, and cardboards, its lifetime on the paper and cotton is much shorter. Therefore, it lasts for a longer time on the hydrophobic materials than on the hydrophilic ones; (c) It is more vulnerable at higher temperatures and drier air. Note that on the basis of Eq. 10, the equilibrium is in favor of the dehydration in such circumstances.

The fact that less water availability in air, compared to an aqueous solution, hydrophilic surfaces, higher temperatures, and drier air all lead to that Eq. 10 shifts to the right, means that the dehydrated virus is thermodynamically more unstable and vulnerable in air. In the other words, the water layer enveloping the virus stabilizes it. Also, water molecules play a crucial role, as an interfacial medium for stabilizing the binding of the virus to the human cell [29]. Therefore, we may infer that any techniques by which the virus becomes dehydrated will be useful for its deactivation. This point 
should be taken into account in making a spray medicine. Such a conclusion may lead us to the following suggestion:

For the closed-contaminated spaces, like indoors in which the covid-19 patients are kept, the air should be circulated and pass over/through a water absorbent material, like calcium chloride. Such a process shifts the equilibrium Eq. 10 to the right. If the time contact of the contaminated air with the deliquescent is enough for the dehydration, we may expect that the virus will be shortly deactivated. If the time is not enough for the adequate dehydration and deactivation, the air should be exposed to the blue or UVC radiations, as well, to deactivate the remaining viruses.

Since sodium chloride and soap kill the virus and a reasonable mechanism is that due to the ion-dipole interaction of the cation with water, the water layer will be pulled away, at least instantly, and then the hydrophobic head of soap and chloride ion get chance to rupture the membrane and attach the electrophilic groups of virus, respectively. Again, the vital step in this deactivation mechanism is the removal of water.

The droplets of spit or oral fluid have different sizes, from less than $1 \mu \mathrm{m}$ up to $100 \mu \mathrm{m}$. Those larger than about $5 \mu \mathrm{m}$ are heavy enough to fall down on the ground and surfaces. The smaller ones can be airborne. Equation 9 suggests that smaller droplets have higher vapor pressure. Therefore, we may expect that the droplets with intermediate size can linger in air for a longer time before losing their water. Also, when a droplet starts missing its water, its farther dehydration is expected to be easier; Eq. 9.

It is worth mentioning that, like the water crisis, global warming, and environmental pollution, COVID-19 pandemic is a global problem. Therefore, global collaboration is needed to manage a globalized society through such crises. In the other words, it is not just a physical phenomenon, but mainly a governance issue related to growing demand combined with unsustainable production approaches, which have negative impact on the environment $[10,50]$.

We have thermodynamically studied the hydrated-dehydrated airborne coronavirus to show how one may fight against the virus.

Acknowledgements Authors acknowledge the support of MegaPrep Academic, in this research project. Also, we would like to acknowledge Jinzhou Tian for his collaboration in preparing the last version of the manuscript.

\section{References}

1. J. Cohen, D. Normile, New SARS-like virus in China triggers alarm. Science 367(6475), 234-235 (2020). https://doi.org/10. $1126 /$ science.367.6475.234
2. Cumulative Number of Reported Probable Cases of SARS. https:// www.who.int/csr/sars/country/2003_07_11/en/

3. Middle East respiratory syndrome coronavirus (MERS-CoV) https://www.who.int/health-topics/middle-east-respiratory-syndr ome-coronavirus-mers \#tab=tab_1

4. Human Coronavirus Types https://www.cdc.gov/coronavirus/ types.html

5. Coronavirus https://www.cdc.gov/coronavirus/types.html

6. J.P. Duguid, The numbers and the sites of origin of the droplets expelled during expiratory activities. Edinb. Med. J. 52(11), 385-401 (1945)

7. M. Nicas, W.W. Nazaroff, A. Hubbard, Toward understanding the risk of secondary airborne infection: emission of respirable pathogens. J. Occup. Environ. Hyg. 2(3), 143-154 (2005). https://doi. org/10.1080/15459620590918466

8. S.A. Boone, C.P. Gerba, Significance of fomites in the spread of respiratory and enteric viral disease. Appl. Environ. Microb. 73(6), 1687-1696 (2007). https://doi.org/10.1128/aem.02051-06

9. S.J. Olsen, H.-L. Chang, T.Y.-Y. Cheung, A.F.-Y. Tang, T.L. Fisk, S.P.-L. Ooi, H.-W. Kuo, D.D.-S. Jiang, K.-T. Chen, J. Lando et al., Transmission of the severe acute respiratory syndrome on aircraft. N. Engl. J. Med. 349(25), 2416-2422 (2003). https://doi.org/10. 1056/nejmoa031349

10. A. Bivins et al., Wastewater-based epidemiology: global collaborative to maximize contribution in the fight against COVID-19. Environ. Sci. Technol. 54, 7754-7757 (2020)

11. G. Medema, L. Heijnen, G. Elsinga, R. Italiaander, A. Brouwer, Presence of SARS-coronavirus-2 RNA in sewage and correlation with reported COVID-19 prevalence in the early state of the epidemic in the Netherlands. Enviro. Sci. Technol. Lett. 7, 511-516 (2020)

12. W. Song, M. Gui, X. Wang, Y. Xiang, Cryo-EM structure of the SARS coronavirus spike glycoprotein in complex with its host cell receptor ACE2. PLoS Pathog (2018). https://doi.org/ 10.1371/journal.ppat.1007236

13. T.R. Ruch, C.E. Machamer, The coronavirus E protein: assembly and beyond. Viruses 4(3), 363-382 (2012). https://doi.org/ $10.3390 / \mathrm{v} 4030363$

14. D. Schoeman, B.C. Fielding, Coronavirus envelope protein: current knowledge. Virol. J. (2019). https://doi.org/10.1186/ s12985-019-1182-0

15. B. Tripet, M.W. Howard, M. Jobling, R.K. Holmes, K.V. Holmes, R.S. Hodges, Structural characterization of the SARS-coronavirus spike S fusion protein core. J. Biol. Chem. 279(20), 20836-20849 (2004). https://doi.org/10.1074/jbc.m400759200

16. N. Vankadari, J.A. Wilce, Emerging COVID-19 coronavirus: glycan shield and structure prediction of spike glycoprotein and its interaction with human CD26. Emerg. Microbes Infects 9(1), 601-604 (2020). https://doi.org/10.1080/22221751.2020.17395 65

17. Symptoms of Coronavirus. https://www.cdc.gov/coronavirus/ 2019-ncov/symptoms-testing/

18. S.A. Lauer, K.H. Grantz, Q. Bi, F.K. Jones, Q. Zheng, H.R. Meredith, A.S. Azman, N.G. Reich, J. Lessler, The incubation period of coronavirus disease 2019 (COVID-19) from publicly reported confirmed cases: estimation and application. Ann. Intern. Med. 172(9), 577-582 (2020). https://doi.org/10.7326/m20-0504

19. V. Stadnytskyi, C.E. Bax, A. Bax, P. Anfinrud, The airborne lifetime of small speech droplets and their potential importance in SARS-CoV-2 transmission. Proc. Natl. Acad. Sci. 117(22), 11875-11877 (2020). https://doi.org/10.1073/pnas.2006874117

20. N.V. Doremalen, T. Bushmaker, D.H. Morris, M.G. Holbrook, A. Gamble, B.N. Williamson, A. Tamin, J.L. Harcourt, N.J. Thornburg, S.I. Gerber et al., Aerosol and surface stability of SARSCoV-2 as compared with SARS-CoV-1. N. Engl. J. Med. 382(16), 1564-1567 (2020). https://doi.org/10.1056/nejmc2004973 
21. M. Jayaweera, H. Perera, B. Gunawardana, J. Manatunga, Transmission of COVID-19 virus by droplets and aerosols: a critical review on the unresolved dichotomy. Environ. Res. 188, 109819 (2020). https://doi.org/10.1016/j.envres.2020.109819

22. K. Li, The link between humidity and COVID-19 caused death. J. Biosci. Med. 08(06), 50-55 (2020). https://doi.org/10.4236/jbm. 2020.86005

23. Y. Liu, Z. Ning, Y. Chen, M. Guo, Y. Liu, N.K. Gali, L. Sun, Y. Duan, J. Cai, D. Westerdahl et al., Aerodynamic analysis of SARS-CoV-2 in two Wuhan hospitals. Nature 582(7813), 557560 (2020). https://doi.org/10.1038/s41586-020-2271-3

24. M. Cascella, M. Rajnik, A. Cuomo, S.C. Dulebohn, R.D. Napoli, Features, Evaluation, and Treatment of Coronavirus (StatPearls Publishing, Treasure Island, 2020)

25 Y.M. Bar-On, A. Flamholz, R. Phillips, R. Milo, SARS-CoV-2 (COVID-19) by the numbers. Elife (2020). https://doi.org/10. 7554/elife.57309

26. K. Rakshit, S. Chatterjee, D. Bandyopadhyay, S. Sarkar, An effective approach to reduce the penetration potential of SARS-CoV-2 and other viruses by spike protein. AIJR (2020). https://doi.org/ 10.21467/preprints.93

27. Q.X. Ma, H. Shan, H.L. Zhang, G.M. Li, R.M. Yang, J.M. Chen, Potential utilities of mask-wearing and instant hand hygiene for fighting SARS-CoV-2. J. Med. Virol. 92(9), 1567-1571 (2020). https://doi.org/10.1002/jmv.25805

28. N.K. Chaudhary, N. Chaudhary, M. Dahal, B. Guragain, S. Rai, R. Chaudhary, K. Sachin, R. Lamichhane-Khadka, A. Bhattarai, Fighting the SARS CoV-2 (COVID-19) pandemic with soap. Preprints 2020050060 (2020)

29. A. Malik, D. Prahlad, N. Kulkarni, A. Kayal, Interfacial water molecules make RBD of SPIKE protein and human ACE2 to stick together. bioRxiv (2020). https://doi.org/10.1101/2020.06. 15.152892

30 A.W. Chin, J.T. Chu, M.R. Perera, K.P. Hui, H.-L. Yen, M.C. Chan, M. Peiris, L.L. Poon, Stability of SARS-CoV-2 in different environmental conditions. medRxiv (2020). https://doi.org/10. 1101/2020.03.15.20036673

31 A. Kratzel, S. Steiner, D. Todt, P. V'kovski, Y. Brueggemann, J. Steinmann, E. Steinmann, V. Thiel, S. Pfaender, Temperaturedependent surface stability of SARS-CoV-2. J. Infect. 81(3), 452-482 (2020). https://doi.org/10.1016/j.jinf.2020.05.074

32. M. Schuit, S. Ratnesar-Shumate, J. Yolitz, G. Williams, W. Weaver, B. Green, D. Miller, M. Krause, K. Beck, S. Wood et al., Airborne SARS-CoV-2 Is rapidly inactivated by simulated sunlight. J. Infect. Dis. 222(4), 564-571 (2020). https://doi.org/10. 1093/infdis/jiaa334

33 J. D'orazio, S. Jarrett, A. Amaro-Ortiz, T. Scott, UV radiation and the skin. Int. J. Mol. Sci. 14(6), 12222-12248 (2013). https://doi. org/10.3390/ijms 140612222

34. C.S. Enwemeka, V.V. Bumah, D.S. Masson-Meyers, Light as a potential treatment for pandemic coronavirus infections: a perspective. J. Photochem. Photobiol. B 207, 111891 (2020). https:// doi.org/10.1016/j.jphotobiol.2020.111891

35. G. Biener, D.S. Masson-Meyers, V.V. Bumah, G. Hussey, M.R. Stoneman, C.S. Enwemeka, V. Raicu, Blue/violet laser inactivates methicillin-resistant staphylococcus aureus by altering its transmembrane potential. J. Photochem. Photobiol. B 170, 118-124 (2017). https://doi.org/10.1016/j.jphotobiol.2017.04.002

36. V.V. Bumah, E. Aboualizadeh, D.S. Masson-Meyers, J.T. Eells, C.S. Enwemeka, C.J. Hirschmugl, Spectrally resolved infrared microscopy and chemometric tools to reveal the interaction between blue light $(470 \mathrm{~nm})$ and methicillin-resistant staphylococcus aureus. J. Photochem. Photobiol. B 167, 150-157 (2017). https://doi.org/10.1016/j.jphotobiol.2016.12.030

37. R.A. Brochetti, M.P. Leal, R. Rodrigues, R.K.D. Palma, L.V.F.D. Oliveira, A.C.R.T. Horliana, A.S. Damazo, A.P.L.D. Oliveira, R.P. Vieira, A. Lino-Dos-Santos-Franco, Photobiomodulation therapy improves both inflammatory and fibrotic parameters in experimental models of lung fibrosis in mice. Lasers Med. Sci. 32(8), 1825-1834 (2017). https://doi.org/10.1007/s10103-017-2281-z

38. H.A. Aboubakr, T.A. Sharafeldin, S.M. Goyal, Stability of SARSCoV-2 and other coronaviruses in the environment and on common touch surfaces and the influence of climatic conditions: a review. Transbound. Emerg. Dis. (2020). https://doi.org/10.1111/ tbed.13707

39. B.M. Henry, M.H.S.D. Oliveira, J. Benoit, G. Lippi, Gastrointestinal symptoms associated with severity of coronavirus disease 2019 (COVID-19): a pooled analysis. Intern. Emerg. Med. 15(5), 857-859 (2020). https://doi.org/10.1007/s11739-020-02329-9

40. E. Price, Could the severity of COVID-19 be increased by low gastric acidity? Crit. Care 24(1), 456 (2020). https://doi.org/10. 1186/s13054-020-03182-0

41. R. Greenaway, K. Ormandy, C. Fellows, T. Hollowood, Impact of hand sanitizer format (gel/foam/liquid) and dose amount on its sensory properties and acceptability for improving hand hygiene compliance. J. Hosp. Infect. 100(2), 195-201 (2018). https://doi. org/10.1016/j.jhin.2018.07.011

42. V. Cecarini, J. Gee, E. Fioretti, M. Amici, M. Angeletti, A.M. Eleuteri, J.N. Keller, Protein oxidation and cellular homeostasis: emphasis on metabolism. BBA Mol. Cell Res. 1773(2), 93-104 (2007). https://doi.org/10.1016/j.bbamcr.2006.08.039

43. M.J. Davies, Protein oxidation and peroxidation. Biochem. J. 473(7), 805-825 (2016). https://doi.org/10.1042/bj20151227

44 R.A. Leslie, S.S. Zhou, D.R. Macinga, Inactivation of SARSCoV-2 by commercially available alcohol-based hand sanitizers. Am. J. Infect. Control (2020). https://doi.org/10.1016/j.ajic.2020. 08.020

45. J.L.J. Jing, T.P. Yi, R.J.C. Bose, J.R. Mccarthy, N. Tharmalingam, T. Madheswaran, Hand sanitizers: A review on formulation aspects, adverse effects, and regulations. Int. J. Environ. Res. Pub. He. 17(9), 3326 (2020). https://doi.org/10.3390/ijerph1709 3326

46. M.-F. Lin, C.-M. Yang, C.-H. Lin, M.-L. Huang, C.-C. Tu, M.-L. Liou, Clinical features and molecular epidemiology of multidrugresistant Acinetobacter calcoaceticus - a baumannii complex in a regional teaching hospital in Taiwan. Am. J. Infect. Control (2009). https://doi.org/10.1016/j.ajic.2009.03.008

47. D. Pittet, Compliance with hand disinfection and its impact on hospital-acquired infections. J. Hosp. Infect. (2001). https://doi. org/10.1016/s0195-6701(01)90012-X

48. M. Winnefeld, M. Richard, M. Drancourt, J. Grob, Skin tolerance and effectiveness of two hand decontamination procedures in everyday hospital use. Br. J. Dermatol. 143(3), 546-550 (2000). https://doi.org/10.1111/j.1365-2133.2000.03708.x

49. P.W. Atkins, Physical Chemistry, 4th edn. (Oxford University Press, Oxford, 1990), p. 148

50. T. van derVoorn, C. van der Berg, P. Bhattacharya, J. Quist, Never waste a crisis: drawing first lessons from COVID-19 pandemic to tackle the water crisis. ACS EST Water 1, 8-10 (2021) 